\title{
Effect of injections of small doses of human fibroblast interferon into genital warts A pilot study
}

\author{
G. M. SCOTT AND G. W. CSONKA \\ From the Division of Communicable Diseases, Clinical Research Centre, Harrow, Middlesex, and the \\ Praed Street Clinic, St Mary's Hospital, London
}

SUMMARY Eleven male patients with genital warts were given injections of fibroblast interferon $(300 \mathrm{u})$ and placebo into the bases of two similar warts. The changes in size of the treated warts compared with that of the controls suggested that interferon did inhibit the growth of the warts. The dose given was probably insufficient for a dramatic effect. In one patient, however, a wart on the penile shaft was injected with interferon and did disappear within two weeks whereas an untreated meatal wart increased in size.

\section{Introduction}

Genital warts (condylomata accuminata) are a common sexually transmissible benign viral infection (Oriel and Almeida, 1970; Oriel, 1971). Treatment is usually with chemical or physical agents and is designed to remove the warty tissue. Infected cells tend to be left behind and the tumour commonly grows again. In a preliminary open study followed by a double-blind study comparing human leucocyte interferon ointment with placebo, interferon was effective in eliminating genital warts in most women treated (Ikić et al., 1975a, b).

This study was designed to see if a single minimal dose of human fibroblast interferon (HFIF) injected into the base of a small genital wart would have any effect on its growth.

\section{Patients and methods}

Twelve male patients (age range 18-32) were admitted to the study. Details of the patients and their warts are shown in Table 1. All except one patient had warts on the penile shaft; the other had fleshy warts in the groin. All except one patient had two small warts of a similar size and appearance; one had a single wart on the shaft and a meatal wart (Patient 4).

Four patients had had warts for six months or longer and repeated applications of podophyllin had failed to remove them completely. Three others had had previous episodes of warts which had been

Address for reprints: Dr G. M. Scott, Division of Communicable Diseases, Clinical Research Centre, Harrow, Middlesex

Received for publication 30 November 1978 temporarily removed by podophyllin or electrocautery; the warts had recurred when treatment was stopped. Three patients experiencing their first attack had received no treatment whereas the other six had had podophyllin treatment which so far had not affected the warts. The most recent podophyllin application took place more than one month before treatment with interferon. Most patients had soft fleshy warts but one (Patient 7) had planar warts resembling verucca vulgaris.

The local ethical committee gave approval for the study; all patients were made conversant with the aims of the experiment and were assured that the treatment would not cure the warts. They then gave their written consent to the experiment.

After the injections the patients were instructed to attend weekly for three weeks. Only seven of the 12 patients complied exactly with the instructions but all except one were seen and assessed at the second or third week after interferon treatment.

\section{PREPARATION OF INTERFERON}

\section{Solution $A$}

The interferon solution used for the experiment was manufactured (G. D. Searle \& Co. Ltd, High Wycombe) by induction of a newly derived foetal lung fibroblast cell line and superinduction using cycloheximide and actinomycin D according to the method of Sehgal et al. (1976). Interferon activity was measured by assessing the dilution which caused a $50 \%$ reduction in the cytopathic effect of Sindbis virus on Vero cells. Assay of the material at the end of the trial to break the code showed that solution A contained $3000 \mathrm{u} / \mathrm{ml}$ of interferon in two separate samples. 


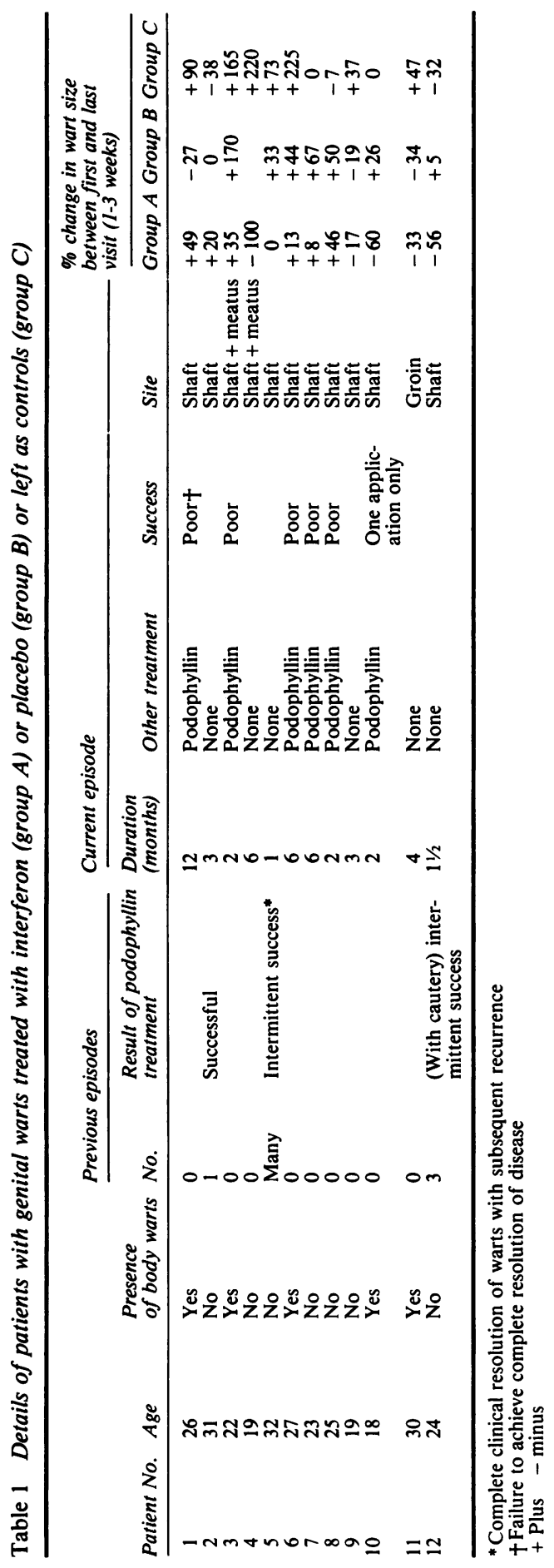

Solution B

The control solution used was a mock fibroblast interferon derived from an abortive induction process and contained no antiviral activity in the above assay.

The cell-line interferon and mock interferon were subjected to stringent tests to ensure the absence of adventitious agents. Previous studies using intradermal injections of high titre fibroblast interferon (Scott et al. 1977, 1978) had shown no toxic effects except for painless local redness occurring four hours after injection and lasting for 24 hours.

\section{INJECTION OF WARTS}

Each volunteer received a single injection of $0.1 \mathrm{ml}$ solution $A(300 \mathrm{u}$ interferon) into the base of one wart (group A warts) and $\mathbf{0 . 1} \mathrm{ml}$ solution B (mock interferon) into another wart of similar size and appearance (group B warts). The materials were packed in single-dose syringes and the investigator was unaware which was the active and which the control solution. (Patient 4, who had one wart on the penile shaft and meatal wart, received an injection of solution A and the meatal wart was left as control.) All the warts not injected with either solution were left as controls (group C). All the warts were measured using dividers transferred to a $\mathrm{mm}$ scale, and the maximum and minimum diameters $(\mathrm{mm})$ were recorded on the first day and then weekly for a maximum of three weeks.

\section{REACTIONS}

All patients reported that the injections caused intense local stinging for 5-10 seconds, but one patient volunteered that the stinging of the injections was less intense than the pain induced by electrocautery. There were mild erythematous reactions at the injection sites at 24 hours and no systemic symptoms.

\section{Results}

The area of the wart was calculated from the maximum ( $\mathrm{d}$ max) and minimum ( $\mathrm{d}$ min) diameters assuming they were elliptical;

$$
\pi(d \max / 2)(d \min / 2)
$$

Excluding patient 4 , the mean size of warts was $10.0 \mathrm{~mm}^{2}$ (range $2 \cdot 4-20$ ) in group $A, 11.3 \mathrm{~mm}^{2}$ $(4 \cdot 7-30)$ in group B, and $36 \cdot 0 \mathrm{~mm}^{2}(5 \cdot 9-165)$ in the uninjected warts (group C). Changes in the size of warts are shown graphically in Figure 1. The proportional change in the size of the warts is shown in Figure 2. 


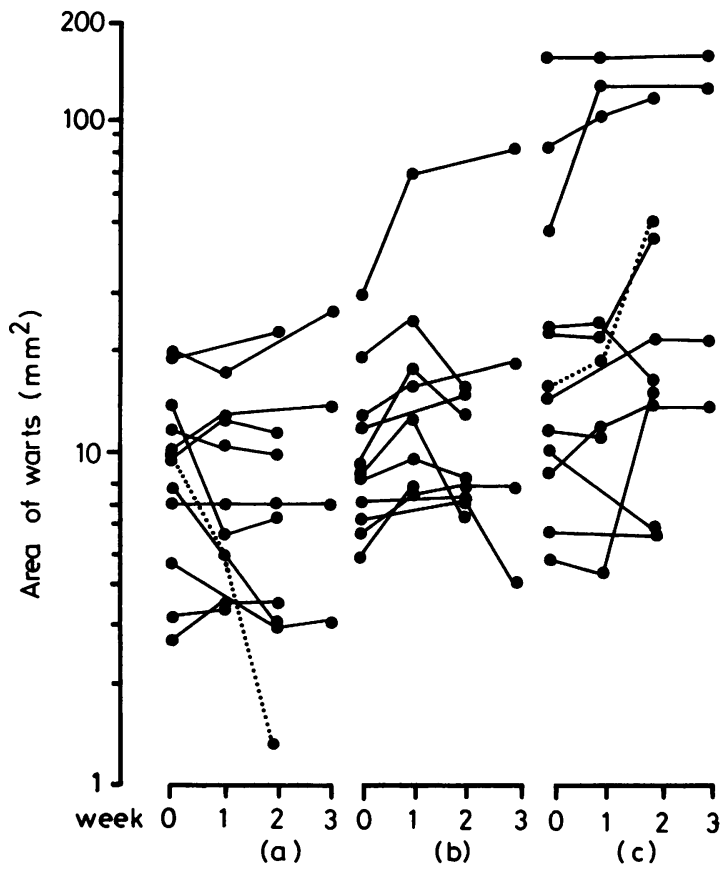

Fig. 1 Change in size of genital warts (a) treated with fibroblast interferon (group $A$ ); (b) treated with mock interferon (group B); and (c) untreated (group C) (. . . . Patient 4 did not receive interferon).
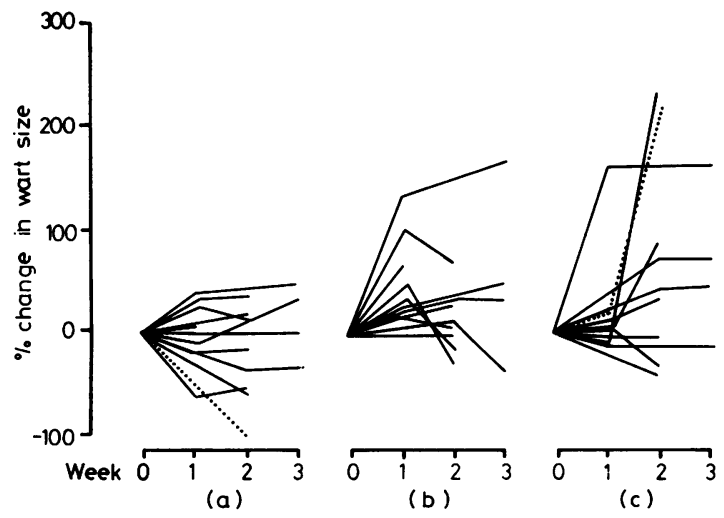

Fig. 2 Proportional change in size of genital warts (a) treated with interferon (group $A$ ); (b) treated with mock interferon (group B); and (c) untreated (group C). Excluding patient $4(. .$.$) the difference between the$ mean geometric change in warts treated with interferon $(-8 \%)$ and those treated with mock interferon (+19\%) plus the untreated warts $(+33 \%)$ is significant $(P=0.045)$. logarithm of the change in size of the warts between the first (pretreatment) and last (at one, two, or three weeks) attendance at the clinic before alternative treatment was instituted (Table 2). Patient 4, treated only with solution $\mathrm{A}$, was excluded from the analysis. Patient 7 was assessed at one week; between the first and third weeks he was inadvertently treated with podophyllin.

The geometric mean of the ratio of the follow-up size to initial size was 0.92 (group A), $1 \cdot 19$ (group $B$ ), and $1 \cdot 33$ (group C). The overall difference between the three groups was not statistically significant. Between group A and groups B plus C, however, the difference was of borderline significance $(P=0.045$, two-tailed test). Thus warts treated with solution A (interferon) grew significantly less than all the other warts including those treated with mock interferon (solution B) and the untreated controls. There was no difference in the response to interferon in patients previously treated with podophyllin.

In the case of patient 4 , a single wart on the penile shaft was treated with solution A (interferon) alone, and by the second week after injection the wart had disappeared leaving a faint scar. Meanwhile the untreated meatal wart had considerably increased in size.

\section{Discussion}

This pilot study indicates that the injection of a small dose of interferon may influence the growth of genital warts compared with that of controls. In one patient the wart injected with interferon disappeared within two weeks. Unfortunately there was no similar wart treated with mock interferon, so the disappearance could have occurred by chance, even though the untreated meatal wart increased in size.

Ikic et al. (1975a, b) studied the effect of relatively impure human leucocyte interferon in an ointment base $(4000 \mathrm{u} / \mathrm{g})$ rubbed into vulval and vaginal warts five times a day. In an open study (Ikić et al., 1975a), 36 of 40 women had complete resolution of their warts by the eighth week of treatment. In a doubleblind study of 20 women with warts (Ikic et al., 1975b), those in the interferon-treated group regressed more frequently than in the placebo group. Regression of the wart took as long as 12 weeks in the treated group but more usually four to five weeks.

The results of this study are encouraging considering the low activity of the interferon solution used. Repeated injections will not be tolerated by these patients and a double-blind comparison of a topically applied preparation of fibroblast interferon with an identical placebo is proposed when material is available. 
Table 2 Analysis of variance on $\log _{10}$ (size of warts after treatment/initial size) in groups $A$ (treated with interferon), $B$ (treated with control), and $C$ (untreated warts)

\begin{tabular}{|c|c|c|c|c|c|}
\hline Source of variation & Sum of squares & $d . f$. & Mean square & Mean square ratio & Significance \\
\hline $\begin{array}{l}\text { Between groups } \\
\text { A vs B } \\
\text { B vs C } \\
\text { A vs B, C } \\
\text { Between patients } \\
\text { Error } \\
\text { Total }\end{array}$ & $\begin{array}{c}0 \cdot 144624 \\
(0 \cdot 066550) \\
(0 \cdot 012768) \\
(0 \cdot 131856) \\
0 \cdot 656321 \\
0 \cdot 576643 \\
1 \cdot 377588\end{array}$ & $\begin{array}{l}2 \\
(1) \\
(1) \\
(1) \\
10 \\
20 \\
32\end{array}$ & $\begin{array}{l}0.072312 \\
0.066550 \\
0.012768 \\
0.131856 \\
0.065632 \\
0.028832\end{array}$ & $\begin{array}{l}2 \cdot 508 \\
2 \cdot 308 \\
0 \cdot 443 \\
4 \cdot 573 \\
2 \cdot 276\end{array}$ & $\begin{array}{l}N S(P>0.1) \\
N S(P>0.1) \\
N S(P>0.1) \\
P=0.045 \\
P=0.056\end{array}$ \\
\hline
\end{tabular}

d.f. $=$ degrees of freedom

NS $=$ not significant

We are grateful to $\mathrm{Mr} \mathbf{J}$. R. Shelton for his statistical advice and to the staff of the Special Clinic, Central Middlesex Hospital, for their help.

\section{References}

Ikić, D., Orescan ain, M., Krusić, J., Cestar, Z., Alac, Z., Soos, E., Jusic, D., and Smerdel, S. (1975a). Preliminary study of the effect of human leukocyte interferon on condylomata accuminata in women. Proceedings of the Symposium on Clinical Use of Interferon, Yugoslav Academy of Sciences and Arts, Zagreb, 223-227.

Ikić, D., Bosnić, N., Smerdel, S., Jusić, D., Soos, E., and Delimar, N., (1975b). Double-blind clinical study with human leukocyte interferon in therapy of condylomata accuminata. Proceedings of the Symposium on Clinical Use of Interferon, Yugoslav Academy of Sciences and Arts, Zagreb, 229-233.
Oriel, J. D. and Almeida, J. D. (1970). Demonstration of virus particles in human genital warts. British Journal of Venereal Diseases, 46, 37-42.

Oriel, J. D. (1971). Natural history of genital warts. British Journal of Venereal Diseases, 47, 1-13.

Scott, G. M., Cartwright, T., Tyrell, D. A. J., Butler, J. K., Porteous, M., and Stevens, R. M. (1977). Preliminary experience with fibroblast interferon against vaccinia virus in human and monkey skin. Proceedings of the Symposium on Preparation Standardization and Clinical Use of Interferon, Yugoslav Academy of Sciences and Arts, Zagreb, 135-142.

Scott, G. M., Cartwright, T., Le Du, G., and Dicker, D. (1978). Effect of human fibroblast interferon on vaccination in volunteers. Journal of Biological Standardization, 6, 73-76.

Sehgal, P. B., Tamm, I., and Vilcek, J. (1976). On the mechanism of enhancement of human interferon production by actinomycin D and cycloheximide. Virology, 70, 256-259. 